\title{
Cowboy Bill Rides Herd on the Range of Consciousness
} MARK JOHNSON

\author{
University of Oregon
}

A mere two decades ago, no self-respecting analytic philosopher would be caught dead espousing a theory of consciousness. It just wasn't done. Talk of some mysterious non-material thing called 'consciousness' would cause hard-minded philosophers to cover their mouths and noses with a hankie and turn away, as though they feared contamination from metaphysical impulses and phenomenological extravaganzas of idle speculation. While it was all right, and even noble, to $b e$ conscious, one certainly was not supposed to have a metaphysical theory of what made it possible to be conscious.

All that seems to have changed in a few short years. Today, you can become a philosophical celebrity just by throwing around a little cognitive neuroscience, talking about the "hard" problem of consciousness, and wrapping the whole subject in mystery. How are we to explain this fairly sudden and radical transition in our thinking about consciousness? What propelled us from the philosophical milieu of the 1950s, $60 \mathrm{~s}$, and $70 \mathrm{~s}$, with its characteristic avoidance of the whole idea of consciousness, to our current fascination with the subject? The answer seems pretty clear. It has been the rise of cognitive neuroscience. The scientific study of cognition has, once again, made it respectable for hard-minded philosophers to talk of consciousness, just so long as they can back up their theoretical speculations with at least some reference to empirical evidence of some sort.

Here's where Cowboy Bill (Willy James, that is) comes riding into view. He's one of the James boys, although his brother, Henry, wasn't much of a cowboy. A century ago he gave us what may be the best account of consciousness ever articulated, and he based it on extensive work in biology, neuroscience, and psychology. James did this, and he

The Journal of Speculative Philosophy, Vol. 16, No. 4, 2002.

Copyright (\$ 2002 The Pennsylvania State University, University Park, PA. 
did something more, something that might still serve us today as a theoretical model for much contemporary cognitive neuroscience. What he did was to give a remarkable phenomenological analysis of aspects of conscious experience, which he tied to what was known at that time about the biological basis of mind, thought, and language.

Whenever I read James on mind, I get this "Aha!" kind of feeling-a sense that what he is saying is right, or could be made right with just a little tweaking. You could back up almost everything he said on the subject with evidence from recent cognitive science, just like he would have done, were he alive today. Let's see how this might work, starting first with James's account, and then measuring it against the work of Antonio Damasio, who has provided one of the more comprehensive contemporary treatments of consciousness from the perspective of cognitive neuroscience.

The first important thing Cowboy Bill tells us is that we humans are inescapably embodied creatures. There is no disembodied "I"-no transcendent ego-that serves as the site of all my experiences and thoughts. There is no disembodied me that thinks my thoughts, feels my feelings, and performs my actions. There is only the continuous flow of thought, experience, and feeling all tied up together, but without any little transcendent self to do the tying up. Cowboy Bill describes our passing thoughts as cattle grazing on the vast range of potential consciousness:

And by a natural consequence, we shall assimilate them [these thoughts] to each other and to the warm and intimate self we now feel within us as we think, and separate them as a collection from whatever selves have not this mark, much as out of a herd of cattle let loose for the winter on some wide western prairie the owner picks out and sorts together when the time for the round-up comes in the spring, all the beasts on which he finds his own particular brand. (James 1950, 333-34)

So, some of Wild Bill's thoughts have the "Lazy WJ" brand on them, which lets him identify those roaming thoughts as "his" and nobody else's. This brand isn't some objectively perceivable mark on the publicly observable roaming mentalstate cattle of the mind. No. It is the felt sense of "warmth and intimacy" that accompanies one particular set of experiences and thoughts, and not others. The cattle of thought are bound together because they resemble each other and because they are somehow continuous with each other, but these two properties are a consequence of the fact that we first feel our thoughts as ours. What Cowboy Bill says about this binding process merits an extended quotation:

For, whatever the thought we are criticising may think about its present self, that self comes to its acquaintance, or is actually felt, with warmth and intimacy. Of course this is the case with the bodily part of it; we feel the whole 
cubic mass of our body existence. Equally do we feel the inner "nucleus of the spiritual self,' either in the shape of yon faint physiological adjustments, or (adopting the universal psychological belief), in that of the pure activity of our thought taking place as such. Our remoter spiritual, material, and social selves, so far as they are realized, come also with a glow and a warmth; for the thought of them infallibly brings some degree of organic emotion in the shape of quickened heart-beats, oppressed breathing, or some other alteration . . . in the general bodily tone. The character of 'warmth,' then, in the present self, reduces itself to either of two things,-- something in the feeling which we have of the thought itself, as thinking, or else the feeling of the body's actual existence at the moment,- - or finally to both. (333)

But just one daggon minute here! Do you expect me to believe that there really is no Cowboy Bill who rounds up his thought-dogies on the range of consciousness? It's startin' to look like there never was any Cowboy Bill in the first place, nobody who could put his Lazy WJ brand on his thought-cattle so he could recognize them as his, when he makes his spring round-up of the self? What's to keep some skunk of a rustler from comin' on in during the night and leadin' off those little dogies, claimin' that they're his? If those dogies aren't mine just because they graze together (continuity) or just because they look alike (resemblance), then why are they mine, anyway?

Now, I think that the answer is this: These little dogies are mine just insofar as they are grazing the range of consciousness that is my embodied self. Thus, in one great sweeping hypothetical stroke, Cowboy Bill points out that "it would follow that our entire feeling of spiritual activity, or what commonly passes by that name, is really a feeling of bodily activities whose exact nature is by most men overlooked" (301-2). Here we confront James's infamous claim that each present thought only incorporates within itself our prior thoughts, just insofar as we feel the warmth and animation that marks them as "mine." Each present thought has to take up into itself only those prior thoughts and experiences that it feels connected to, that is, that it experiences with warmth and intimacy.

If I thought of each of my present thoughts as a distinct moment of consciousness, then, to pose Hume's problem all over again, what would bind them all together? Cowboy Bill insists that what binds my thoughts together is only the felt sense of connection, when a present thought warmly recognizes a preceding thought:

A uniform feeling of 'warmth,' of bodily existence (or an equally uniform feeling of pure psychic energy?) pervades them [our past and present selves] all; and this is what gives them a generic unity, and makes them the same in kind. (335)

Well, partner, are you beginnin' to think that Cowboy Bill's been alone too long on the range of consciousness? Even on a charitable interpretation, it looks like 
maybe he's been eatin' too many beans and drinkin' bad whiskey. Sometimes it looks like all he's sayin' is that you sure as heck know your own dogies when ya see 'em (or maybe smell 'em).

Since I was brought up in Kansas, about fifty miles from where "Home on the Range" was written, and since I've subsequently moved to the wild west out beyond the Rocky Mountains, I've become somewhat partial to Cowboy Bill's open-range metaphors for mind. I want to leap ahead a century or so in order to compare Cowboy Bill's proposal with some more recent reports of scouting parties on the contemporary range of consciousness. I'm talking about present-day cognitive science.

The cowpoke I want to focus on most is someone who rides herd on the prairies of Iowa. I'm talking about Antonio Damasio, the cognitive neuroscientist who has written so eloquently on the nature of mind, consciousness, thought, and feeling (see Damasio 1994 and 1999). What he tells us is that the best available evidence from neuroscience today reveals that Cowboy Bill was more or less right in many aspects of his view of consciousness and thought. What both these cowpokes tell us is this: The mind is embodied, thought is tied to feeling, and consciousness is a matter of feeling our body-states.

The details of this new account form a difficult and incredibly complicated story, one that requires forays into brain anatomy, neuron functioning, neurochemical bases of emotions, brain lesion studies, philosophy, and psychology. However, a grotesquely oversimplified account would go something like this: Damasio identifies two major problems concerning consciousness. The first is to explain how the brain, operating within an embodied organism that is interacting continually with its environment, can have mental images of objects, events, thoughts, feelings, and actions." The second problem is "how, in parallel with engendering mental patterns for an object, the brain also engenders a sense of self in the act of knowing" (Damasio 1999, 9). This sense of a unified self is our sense that our experience and ideas are ours, as if we "owned" them. Damasio's grand hypothesis is that your sense of self involves the feeling of what is happening to you-the feeling of how "your being is modified by the acts of apprehending something" (10).

Damasio begins his account of consciousness by stressing the crucial fact that we are dynamic organisms defined by boundaries and the maintenance of balanced states within those boundaries. To live, we must continually maintain our internal milieu by monitoring and altering, when necessary, water, salts, gasses, minerals, hormones, nutrients, and so on. Damasio speculates that, whatever other purposes consciousness eventually came to serve for us, it first emerged as our way of preserving a stable internal milieu, in light of changing environmental conditions, and it never ceases to perform that most essential life-sustaining function.

So the question is, how does consciousness operate in the monitoring of our body states? The answer is, by feeling. One of Damasio's pivotal ideas is that 
emotions are based on neuro-chemical processes by which the embodied organism monitors changes in its internal situation and is thereby alerted to the need for appropriate responses to changing conditions in the organism-environment interaction. Damasio distinguishes between emotions and feelings. He preserves the word "feeling" for our awareness of the quality of a given emotion or emotional contour. In other words, we can and do have emotional experience that we are not conscious of. Such emotions are registered throughout our bodies and brains, but we remain blithely unaware of all this ongoing life-monitoring activity. Only on those occasions when we become conscious (i.e., aware) of the ebb and flow of our emotional events do we then "feel" them as ours and experience their distinctive qualities. In short, we are affected by objects and events both from within and outside us, and we sometimes feel our self as being affected by these events. In this way, we develop a sense of a particular flow of experience as belonging to us.

On the basis of this account of body-state monitoring via emotions and feelings, Damasio builds a theory of types of consciousness and their relation to three types of self. He begins with the "proto-self," which is "a coherent collection of neural patterns which map, moment by moment, the state of the physical structure of the organism in its many dimensions" $(1999,154)$. There is no consciousness for this proto-self, no consciousness of the body's mapping of its current physical state, even though our very life depends on such activity. We couldn't survive if we had to consciously attend to all of this life-sustaining activity. Nor is the proto-self a single substantial unity, either. Rather, "it emerges dynamically and continuously out of multifarious interacting signals that span varied orders of the nervous system" (154).

Consciousness first emerges as what Damasio calls a "core consciousness" (with its correlative "core self"), which adds to the proto-self an awareness of how we are being affected by aspects of our environment at the present moment in time. Here, too, this is a matter of feeling ourselves being affected by something. What we are feeling in this case are changes in our bodily state in the present moment of experience (as "here and now"), and we are feeling these feelings as ours. In Damasio's words,

Core consciousness occurs when the brain's representation devices generate an imaged, nonverbal account of how the organism's own state is affected by the organism's processing of an object, and when this process enhances the image of the causative object, thus placing it saliently in a spatial and temporal context. (169)

To translate: the core self thus makes use of the proto-self's body-state mapping in order to become aware of how it is being affected by objects, events, and internal images and occurrences. This "nonverbal account" that we develop is not linguistic. Instead, it involves a mapping in the brain of images, feelings, and 
emotions. It is the organism's non-linguistic felt awareness of the "act of representing its own changing state as it goes about representing something else" (170). It is the feeling of what is happening to us at the present moment, just as Cowboy Bill said a century ago.

However, our experience of the mere present moment is not, except in cases of extreme psychological dysfunction, an isolated event. ${ }^{2}$ Successive moments of core consciousness are bound together in what Damasio calls "extended consciousness," that is, our capacity to connect the present with the remembered past and an anticipated future. Extended consciousness is what makes possible our "autobiographical self," our sense of ourselves as extended continuously over a span of time and thereby living out a narrative drama. Damasio does not pretend to have a fully adequate explanation of extended consciousness, but he makes it quite clear that two basic "tricks," as he calls them, are required to accomplish extended consciousness. The first trick is to build up memories of the felt images of prior experiences of the organism, as they unfolded in its past history. The second trick is what neuroscientists call a "binding problem," namely, to "hold active, simultaneously and for a substantial amount of time, the many images whose collection defines the autobiographical self and the images which define the object. The reiterated components of the autobiographical self and the object are bathed in the feeling of knowing that arises in core consciousness" (Damasio 1999, 198).

I believe that what Damasio is describing here as "the feeling of what happens" to us is precisely the phenomenon Cowboy Bill described as a "feeling of warmth and intimacy" in the process by which a present moment (of core consciousness) enfolds within it previous moments of the embodied organism. Both Damasio and James think that there is only a stream of consciousness and that "consciousness is not a monolith" (121). Nonetheless, consciousness does involve a set of real phenomena that cannot be reduced simply to memory, wakefulness, low-level attention, language, or reasoning, even though in humans it is intimately connected to all of these crucial functions at the level of extended consciousness. None of this can exist without emotion, since all monitoring of our changing states and images (arising both internally and externally) occurs via emotions. There is no single self that is the locus of consciousness; instead, there is a vast orchestration of processes at multiple levels that conjointly give rise to our "feeling of what happens." James thinks that what binds our successive awarenesses together is our present thought as it appropriates, through its feeling of its bodily states, prior thoughts. In his words, the present thought's "appropriations are therefore less to itself than to the most intimately felt part of its present Object, the body, and the central adjustments, which accompany the thinking, in the head. These are the nucleus of our personal identity ..." (James 1950, 341).

Reflecting on these two parallel accounts of the role of emotions in the unity of consciousness also sheds light on something in Dewey that has always puz- 
zled and irritated me. I refer to his wild claim that it is properly situations that are characterized by emotionality, rather than merely a person's mind or psychic state. How can situations be fearful, where there is no consciousness possessed by the situation that could experience the fear?

Well, the answer, we see, is that consciousness is in and of the situation as it is felt. It resides neither in organism nor environment separately, but rather in the process of interactions that jointly constitutes an organism and its environment. As Damasio argues, we are typically not aware of the process of our body forming images of things it is experiencing. We don't feel that unconscious experiencing directly. But what we can and do feel is "how the organism's own state is affected by its processing of an object" (Damasio 1999, 169). Note that we feel our being affected, and we feel this as connected to our own body. It is only our embodiment that can hold core consciousness together in a moment of our experience and give us the basis for a unified identity.

At this deep level, I submit, it makes no sense to radically distinguish "mind" from "body." Our feeling of how we are affected by images is neither in the external environment nor in our psychic state, but rather, it dwells in both at once. That is, it dwells in the body as it experiences the world and the world as it is felt through its influence on the organism. The reason that Dewey can think of feelings as objective qualities of entire situations is that the situation is what and how it is only in and through the pervading felt quality that distinguishes it. As Dewey says in his important essay, "Qualitative Thought" (1929-30, 242-62), the quality is not a mere property of some aspect of the situation. To think of it that way is a mistake based on trying to abstract the quality from the situation. Dewey explains this by reference to the pervasive quality that distinguishes a particular work of art: "Its quality is not a property which it possesses in addition to its other properties. It is something which externally demarcates it from other paintings, and which internally pervades, colors, tones, and weights every detail and every relation of the work of art" (245).

Dewey and James saw that we are not conscious of generic experiences. We are conscious of particular situations, as we feel them with all their peculiarities at the level of our embodied interactions with our environment. What Damasio adds to this is the beginnings of an account of the neuro-chemical processes that make possible our felt sense of the quality of a particular situation. In short, our first and most primordial encounter with the world is emotional through and through. Our world is as it is for us most fundamentally as we feel it and feel ourselves as affected by it. This is as close as I can come to Dewey's idea of locating the felt quality as demarcating and pervading the whole situation at a given movement.

What is most stunning about all of this, for me, is its recognition of the crucial role of emotion and feeling in everything we experience, think, and do. Our world and our self are conjointly bound together in an inseparable way via embodied feeling. The abstractions that populate our thinking do not transcend 
such feelings; rather, they are articulations of the abstract structure of those feelings. And so we all know that our thought can never do full justice to our feelings or to the pervasive qualities that characterize situations. This is the fact capitalized on by philosophers fascinated by anti-reductivist "qualia" arguments. None of this should lead us to some of the more mystical claims about qualia that populate the contemporary debate on the subject of consciousness. It should only make us humble in the face of the fact that our abstractions cannot present the fully embodied felt sense of a situation that makes both situation and ourselves what and who they are.

So, we ride off into the sunset on the range of consciousness. In the last analysis, what is misleading about Cowboy Bill's metaphor of the herd is that it postulates the "cowboy" who rides herd. There is no substantial cowboy-self who rides herd and recognizes brands. The cowboy can only be the present moment that enfolds, via feeling, some of its past body-states within itself and projects possibilities for future experience. Cowboy Bill, you are at once nobody and the only somebody there is. You seem to be one of the cows, one of the little dogies, who, in the next moment, will be recognized with warmth and intimacy by another little dogie roaming the vast range of consciousness. It is the only self we have, and it will perhaps be a little scary for us as we feel the chill of the high desert night air and hear the lonely howling of the coyotes somewhere out beyond the dim light of the campfire.

\section{Notes}

1. By "mental images" Damasio does not mean internal visual pictures. Rather, he uses this term for any of a wide variety of so-called representations or patterns of interaction that come to a person both through sensory perception or from changes in our internal states.

2. Damasio presents examples of patients who have suffered brain lesions and who experience their own present moment, but who have no coherent sense of themselves extending over time, since they have no extended memory.

\section{Works Cited}

Damasio, Antonio. 1994. Descartes' Error: Emotion, Reason, and the Human Brain. New York: G. P. Putnam's Sons.

1999. The Feeling of What Happens: Body and Emotion in the Making of Consciousness. New York: Harcourt, Brace, \& Co.

Dewey, John. 1988. “Qualitative Thought," In The Later Works of John Dewey, 1925-53, Volume 5, ed. Jo Ann Boydston, 242-62. Carbondale: Southern Illinois UP.

James, William. 1950. The Principles of Psychology, vol. 1, 1890. New York: Dover. 